\title{
ESTROMATÓLITOS DO GRUPO ITAIACOCA AO SUL DE ITAPEVA, ESTADO DE SÃO PAULO, BRASIL
}

\author{
WILLIAM SALLUN FILHO \\ Curso de Pós-Graduação, Instituto de Geociências, USP, Rua do Lago, 562, 05508-080, São Paulo, SP, Brasil. \\ wsallun@usp.br \\ THOMAS RICH FAIRCHILD \\ Instituto de Geociências, USP, Rua do Lago, 562, 05508-080, São Paulo, SP, Brasil.trfairch@hotmail.com
}

\begin{abstract}
RESUMO - Três morfotipos estromatolíticos colunares foram identificados no Grupo Itaiacoca (Proterozóico) na região ao sul de Itapeva, São Paulo. O mais comum é atribuível a Conophyton por sua laminação coniforme e zona axial. Os outros dois morfotipos, de laminação marcadamente convexa mas não coniforme, diferem entre si em tamanho, silhueta e ramificação. As pedreiras Indumine e Lavrinhas se destacam pelo abundância de Conophyton, pelos ambientes deposicionais e grau de deformação. Nestas localidades, os estromatólitos, quase exclusivamente Conophyton, constituem dois tipos distintos de bioermas: um tabular, mais extenso e dolomítico (Lavrinhas), e outro lenticular, isolado e calcítico (Indumine). A dominância de Conophyton e a ausência de indicadores de águas rasas sugerem águas relativamente profundas em ambas localidades. O crescimento diferenciado dos estromatólitos nos dois bioermas é atribuído a diferenças na luminosidade e/ou profundidade. Em Lavrinhas, o maior diâmetro, freqüente coalescência e desenvolvimento lateral das colunas, juntamente com a baixa percentagem de impurezas siliciclásticas no dolomito, sugerem águas mais límpidas e/ou mais rasas, permitindo expansão lateral. Em Indumine, a forma colunar mais delgada, as raras coalescências, a impureza dos calcários e a própria lenticularidade do bioerma indicam um crescimento acentuadamente vertical, heliotrópico, como esperado em águas mais turvas ou profundas.
\end{abstract}

Palavras-chave: Estromatólitos, Conophyton, Grupo Itaiacoca, Proterozóico.

ABSTRACT - STROMATOLITES OF THE ITAIACOCA GROUP AT SOUTH OF ITAPEVA, SÃO PAULO STATE, BRAZIL. Three columnar stromatolite morphotypes were recognized in the Itaiacoca Group (Proterozoic) to the south of Itapeva, São Paulo. The commonest is assignable to Conophyton on the basis of its coniform lamination and axial zone. The other two forms, with markedly convex but not coniform lamination, differ in size, silhouette and branching. The Indumine and Lavrinhas quarries are outstanding for their abundance and preservation of Conophyton, for their depositional environments and styles of deformation. At both localities, the stromatolites occur in bioherms: tabular and more extensive in the dolostone at Lavrinhas, and lenticular and isolated in the limestone at Indumine. The predominance of Conophyton and the absence of shallow water indicators suggest a deep water environment at both sites. The growth habits of the stromatolites in these two bioherms may be attributed to differences in luminosity and/or relative depth at the two sites. At Lavrinhas, the large column diameters, frequent lateral coalescence and development of the stromatolites, and low siliciclastic content suggest that the water was clear and/or shallow, allowing lateral expansion. At Indumine, the narrow columns, rarity of coalescence, high percentage of siliciclastic impurities in the limestone as well as the great lenticularity of the bioherm point to accentuated vertical heliotropic growth, consistent with deposition in mud or deeper water.

Key words: Stromatolites, Conophyton, Itaiacoca Group, Proterozoic.

\section{INTRODUÇÃO}

Estromatólitos são estruturas biossedimentares originadas por atividade microbiana que ocorrem desde o Arqueano até hoje. São mais abundantes nas sucessões carbonáticas do Proterozóico, como em unidades proterozóicas das faixas
Ribeira e Paraguai no Brasil, e nas coberturas e faixas dobradas associadas ao Cráton do São Francisco.

No Brasil, os primeiros estromatólitos foram descritos na Faixa Ribeira na região de Itapeva (SP) e denominados Collenia itapevensis (Almeida, 1944; Fairchild \& Sallun Filho, no prelo). Posteriormente, Almeida (1957) reportou ou- 
tras ocorrências de estromatólitos da mesma faixa dobrada entre Itapeva (SP) e Itaiacoca (PR), em carbonatos que ele denominou de Formação Itaiacoca (agora Grupo Itaiacoca). Fairchild (1977) retomou o estudo dos estromatólitos da região ao sul de Itapeva, nas localidades descritas por Almeida (1944), chamando atenção à diferença destes em relação aos estromatólitos, ainda não classificados, da Formação Capiru, mais a sudeste na Faixa Ribeira. Reconheceu em Collenia itapevensis duas formas distintas, uma das quais provavelmente Conophyton garganicum, conhecida no Neoproterozóico inferior e Mesoproterozóico de outras partes do mundo, e a outra uma forma colunar ramificada. $\mathrm{O}$ presente trabalho, sintetiza os resultados desses estudos, descreve os estromatólitos ao sul de Itapeva e esclarece sua origem.

\section{Contexto geológico}

O Grupo Itaiacoca aflora na faixa de dobramentos homômina que se estende $\mathrm{NE}-\mathrm{SW}$, desde a região de Guapiara e Itapeva em São Paulo, até Itaiacoca no Paraná, dentro da Faixa Ribeira do Sudeste do Brasil. Os limites do Grupo Itaiacoca a noroeste e a sudeste se dão com os Complexos Graníticos Cunhaporanga e Três Córregos (Neoproterozóico superior-Eopaleozóico), respectivamente; e a nordeste e sudoeste com os sedimentos paleozóicos da Formação Furnas e do Subgrupo Itararé (Bacia do Paraná) em discordância angular e erosiva. É distinto e independente do Grupo Açungui, também conhecido por seu conteúdo estromatolítico (Bigarella \& Salamuni, 1958; Marini et al., 1967; Marini \& Bósio, 1971; Fairchild, 1977, 1982), que aflora a sudeste do Complexo Três Córregos. Embora descrito, inicialmente, com ênfase na sua parte carbonática, o Gupo Itaiacoca engloba uma associação vulcano-sedimentar, seguida por outra químico-pelítica (Trein et al., 1985; Theodorovicz et al., 1986; Souza, 1990; Reis Neto, 1994; Prazeres Filho et al., 1998). Dentre os metacalcários, distinguem-se metacalcários dolomíticos e calcíticos, alguns dos quais estromatolíticos. Inexiste uma estratigrafia regional refinada para o grupo devido às complicações estruturais, grande variação faciológica, poucos dados geocronológicos e ausência de bons marcos estratigráficos, inclusive de fósseis, exceção feita talvez à presença de estromatólitos em diversas localidades. A deformação afetou, ainda, os estromatólitos, em maior ou em menor grau, chegando, em alguns casos, a obliterá-los. Sallun Filho (1999) aborda mais detalhadamente esta questão. A idade do Grupo Itaiacoca é, ainda, um assunto controverso. Contudo, pesquisas recentes apontam para sedimentação mais antiga que $635 \mathrm{Ma}$, idade obtida por Siga Jr. et al. (2003) em rochas metavulcânicas. Estudos anteriores (Fairchild, 1977; Reis Neto, 1994) sugeriram uma idade mesoproterozóica.

\section{Material e métodos}

Os estromatólitos foram estudados principalmente em pedreiras e pequenas frentes, muitas atualmente inativas, abertas ao longo dos últimos 60 anos ou mais. Amostras representativas foram coletadas (algumas com até $50 \mathrm{~kg}$ ) para estudo, em laboratório, a partir de cortes longitudinais e transversais polidos. Lâminas delgadas mais espessas do que as petrográficas habituais foram confeccionadas para examinar aspectos texturais e detalhes da laminção. Algumas amostras foram dissolvidas em ácido clorídrico para determinar a percentagem de impurezas no carbonato. O material analisado está depositado nas coleções do Laboratório de Paleontologia Sistemática do Instituto de Geociências da Universidade de São Paulo (LPS/IG-USP).

Adotaram-se critérios morfológicos os mais objetivos possíveis para diferenciar os morfotipos estromatolíticos (Hofmann, 1969; Fairchild, 1993), evitando-se aplicar a classificação taxonômica disponível para estromatólitos, já que carece de critérios biológicos hierárquicos. Uma exceção é feita no caso dos estromatólitos cônicos (Conophyton), cuja diferenciação, baseada na morfologia quase geométrica de sua laminação, é mais objetiva.

\section{PRINCIPAIS OCORRÊNCIAS}

Das nove ocorrências de estromatólitos investigadas ao sul de Itapeva (SP), cinco se destacam: Pedreira Lavrinhas, Pedreira Indumine /Chiquino de Barros, Fazenda Santo Antônio, Nova Campina e Brancal-Indumine I (Figura 1).

\section{Pedreira Lavrinhas}

A frente ativa da Pedreira Lavrinhas (Ponto A1, Figura 1) são metacalcários dolomíticos, sem estromatólitos, que só preservam a estratificação (N50E/70-80NW), sem estruturas sedimentares. No entanto, em duas frentes abandonadas a sul e sudeste (Ponto A2, Figura 1) (UTM: 722.552, 7333.017; 722.434, 7332.990), observou-se a presença de estromatólitos na base da sucessão. Nestas frentes, os metacalcários dolomíticos cinza claros são abundantemente estromatolíticos, embora os contornos e a laminação dos estromatólitos, originalmente ressaltados pelo conteúdo de matéria orgânica, tenham ficado apagados. Mesmo assim, este ponto representa, atualmente, a melhor exposição de estruturas estromatolíticas nos metacalcários dolomíticos da região. O pacote estromatolítico estende-se lateralmente por toda a largura da exposição, no mínimo $70 \mathrm{~m}$, e por cerca de $50 \mathrm{~m}$ de espessura, mas quase não apresenta acamadamento discernível devido à forma de acumulação e tamanho aparentemente métrico dos agregados de estromatólitos colunares que constituem o pacote. Subindo na seção, o acamadamento só se torna conspícuo onde os estromatólitos cedem lugar a metacalcários dolomíticos estratificados no lado sudoeste da pedreira e na pedreira ativa de Lavrinhas (Figura 2).

A maioria dos estromatólitos apresenta forma colunar cônica decimétrica, atribuível a Conophyton. Os eixos des- 

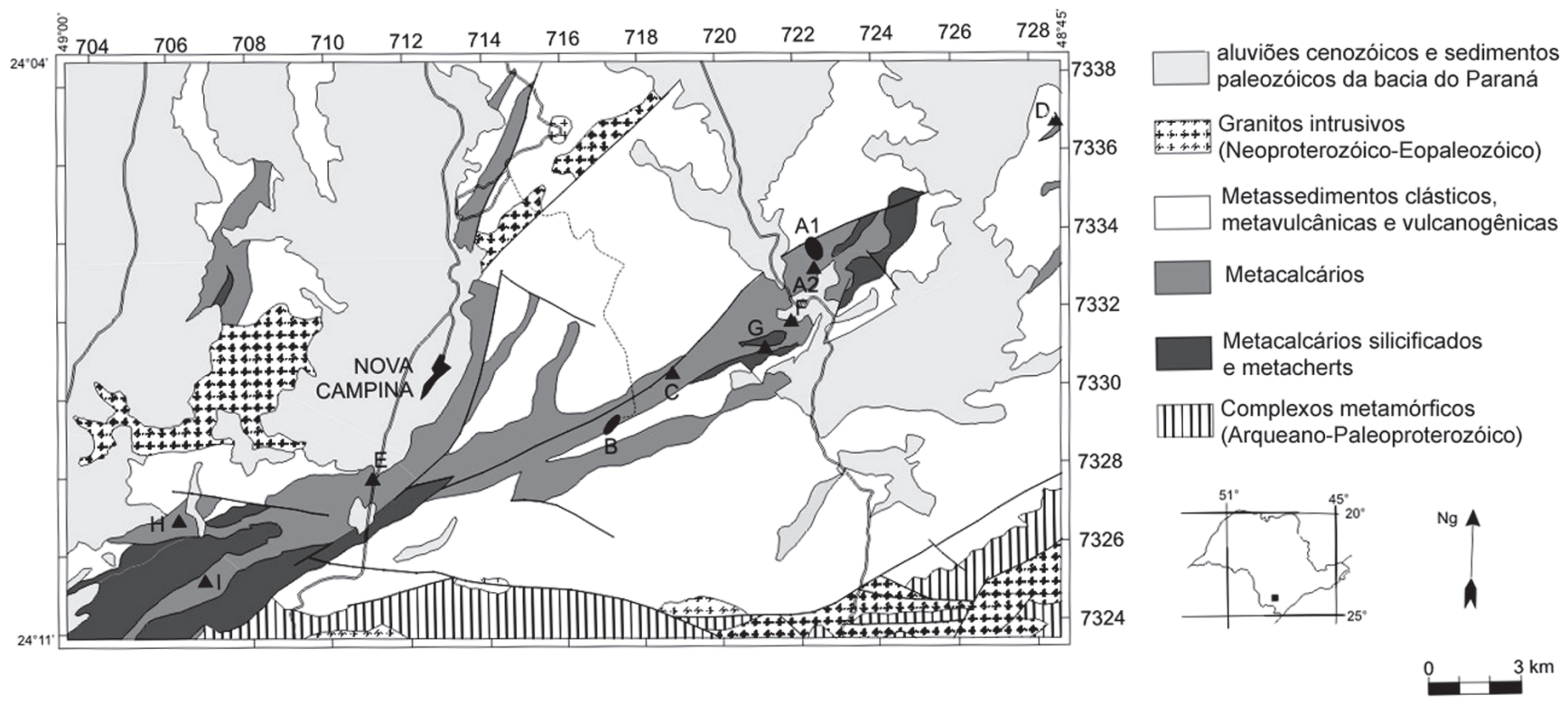

Figura 1. Mapa geológico com as ocorrências de estromatólitos: A, Lavrinhas (A1, ativa; A2, abandonadas). B, Indumine. C, Chiquinho de Barros. D, Fazenda Santo Antônio. E, Nova Campina. F, Brancal-Indumine I. G, Brancal-Indumine II. H, Itanguá. I, Taquari Guaçu (modificado de Theodorovicz et al., 1986).

Figure 1. Geologic map with stromatolite occurrences: A, Lavrinhas (A1, active; A2, abandoned). B, Indumine. C, Chiquinho de Barros quarry. D- Fazenda Santo Antônio. E, Nova Campina. F, Brancal-Indumine I. G, Brancal-Indumine II. H, Itanguá. I, Taquari Guaçu (modified from Theodorovicz et al., 1986).

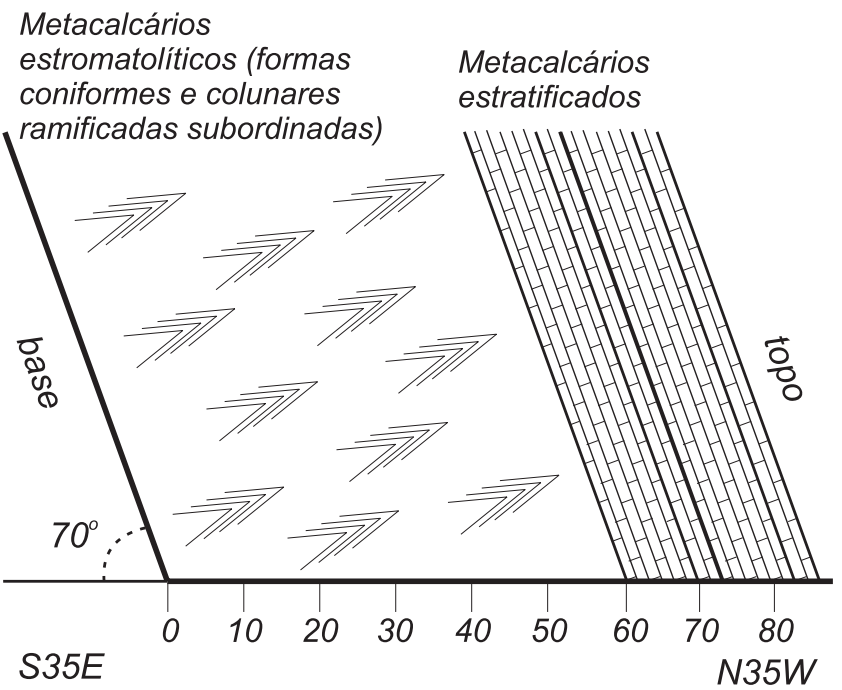

Figura 2. Seção estratigráfica esquemática da frente abandonada da pedreira Lavrinhas.

Figure 2. Schematic stratigraphic section of the abandoned quarry at Lavrinhas.

ses estromatólitos mergulham $40^{\circ}$ para S20W com o topo para NE (Figura 2). Ocorrem muito próximos entre si, podendo haver coalescência de colunas nas margens de bioermas (Figura 3A). Outras duas formas de estromatólitos, também colunares, mas centimétricos, foram encontrados num único ponto desta pedreira. Todos os estromatólitos apresentam alternância de tonalidades cinza claro e cinza médio, e sedimento intercolunar cinza médio.

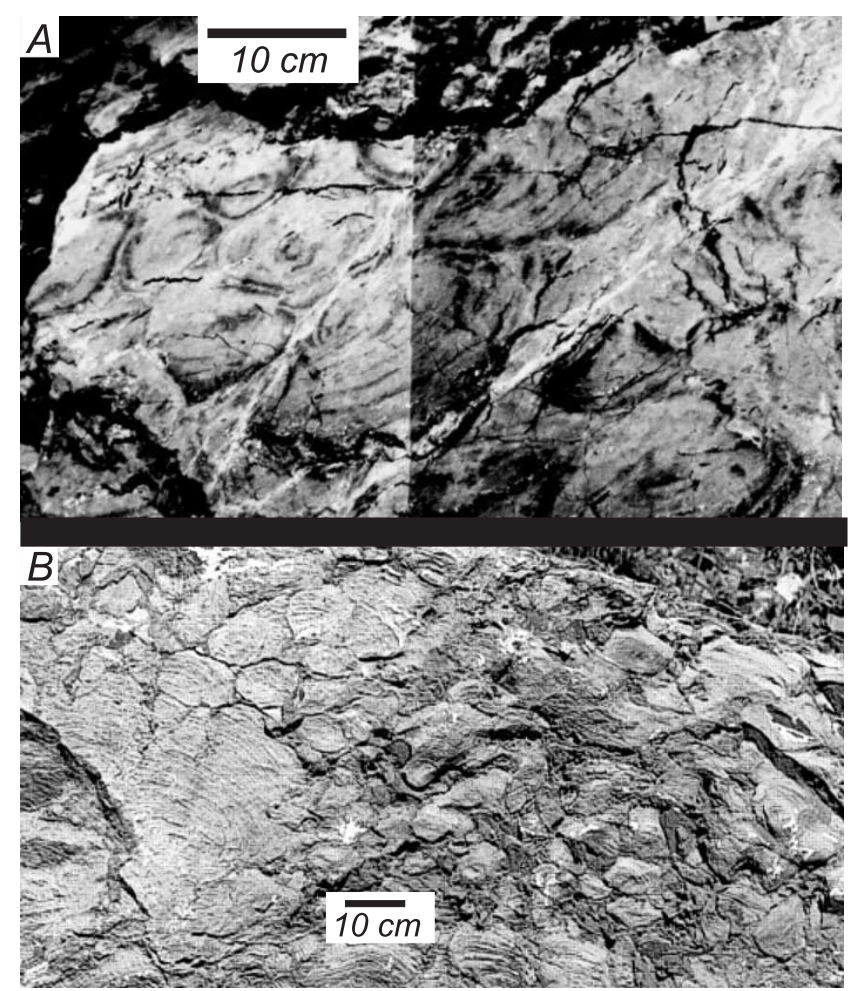

Figura 3. Vistas em planta de agrupamentos de estromatólitos colunares coniformes (Conophyton) exibindo coalescência lateral nos metadolomitos de Lavrinhas $(\mathbf{A})$ e nos metacalcários calcíticos de Indumine (B).

Figure 3. Plan views of coniform columnar stromatolite groups (Conophyton) showing lateral coalescence in the metadolomites at Lavrinhas (A) and in the metalimestones at Indumine (B). 


\section{Pedreira Indumine/Chiquinho de Barros}

A Pedreira Indumine (Ponto B, Figura 1; UTM: 717.100, 7329.001) é uma mina ativa desenvolvida em metacalcários calcíticos estromatolíticos cinza escuros a negros, bastante argilosos e foliados, muito distintos dos metacalcários dolomíticos claros de Lavrinhas. O corpo metacalcário em exploração representa assim um grande bioerma (Figura 4A). Em superfícies não alteradas, os estromatólitos são praticamente indistinguíveis do sedimento entre as colunas. Por isso, são as superfícies intemperizadas onde as estruturas estão ressaltadas. Os estromatólitos são colunares, retos (agora deformados), praticamente todos coniformes, atribuíveis a Conophyton. Os eixos das colunas mergulham $40^{\circ}$ para S50W, com o topo para nordeste. A sucessão neste local inicia-se com filitos, na base, passando por metacalcários arenosos e, depois, metacalcários estromatolíticos com, no mínimo, 20 m de espessura e recobertos por metarenitos finos (Figura 4B). Filitos ocorrem na porção leste da pedreira, sobre os metacalcários em contato brusco, e na porção sudoeste, onde também recobrem os metacalcários, em contato gradual.

As duas pedreiras Chiquinho de Barros (Ponto C, Figura 1) estão localizadas a aproximadamente $1,5 \mathrm{~km}$ a nordeste da Pedreira Indumine, na estrada entre Indumine e Brancal, na altura do Bairro dos Tavares. São duas frentes abandonadas: uma ao lado da estrada (exposição menor) e a outra situada acima, afastada da estrada (UTM: 718.736, 7330.354; 718.785, 7330.535). São metacalcários calcíticos cinza escuros estromatolíticos, semelhantes aos da Pedreira Indumine. Ocorrem estromatólitos colunares, especialmente na segunda frente, mas não foi possível fazer descrições mais detalhadas, pois a vegetação dificulta o acesso. Assim, a análise destes estromatólitos se deu através de amostras, descrições e fotografias.

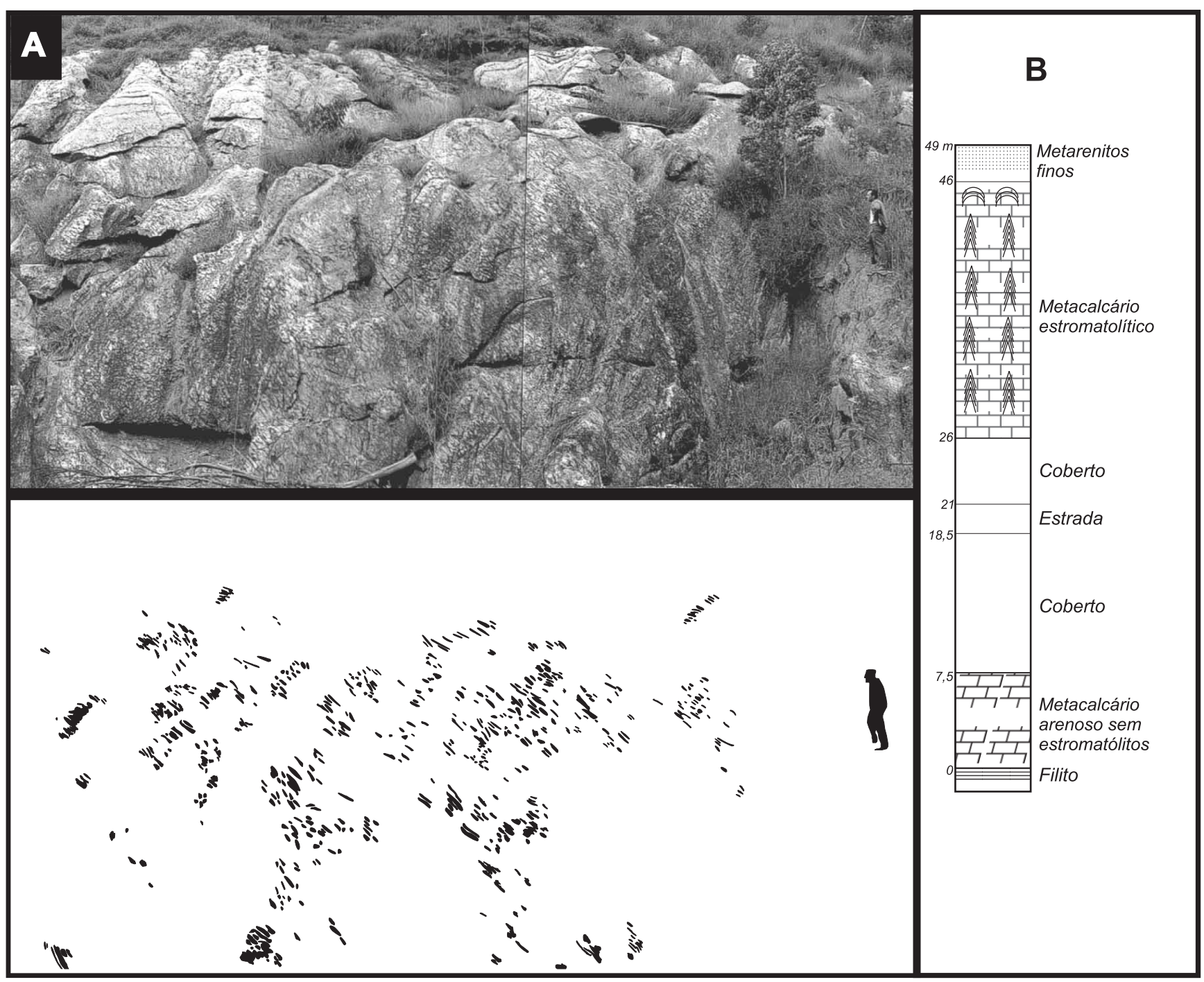

Figura 4. Pedreira Indumine: A, visão geral dos estromatólitos (superior) com realce das colunas mais evidentes (inferior); B, seção estratigráfica esquemática.

Figure 4. Indumine quarry: A, general view of stromatolites (upper) with more evident columns outlined (lower); B, schematic stratigraphic section. 


\section{Fazenda Santo Antônio}

Na Fazenda Santo Antônio (Ponto D, Figura 1), no ponto mais nordeste da área de estudo (UTM: 728.933, 7337.041), foi aberta frente para exploração comercial de metacalcário dolomítico bandado preto, branco e vermelho. Os metacalcários dolomíticos apresentam-se intensamente deformados e recristalizados, com bandamento orientado N65E/ 65SE e as faixas vermelhas estromatolíticas, menos recristalizadas, apresentando budinagem (Figura 5). Dois planos verticais orientados $\mathrm{N}-\mathrm{S}$ foram deixados pela extração, a poucos metros um do outro (Figura 5A). Estes cortes são oblíquos tanto aos eixos dos estromatólitos, quanto ao bandamento da rocha. $\mathrm{O}$ maior ( $15 \mathrm{~m}$ de comprimento) encontra-se coberto por limo. O corte menor (10 m de comprimento), mais recente e mais limpo, permitiu observar (Figura 5) estromatólitos densamente agrupados, retos, colunares, não ramificados e com margens preservadas. Exibem no máximo $10 \mathrm{~cm}$ de largura e no mínimo $20 \mathrm{~cm}$ de altura, mas estão interrompidos pela deformação. A laminação é milimétrica com relevo sinótico relativamente alto. Cortes longitudinais feitos em laboratório revelaram a forma cônica da laminação, diferente daquela de relevo baixo nos cortes oblíquos vistos no campo, e também a presença de zona axial, comprovando a presença de Conophyton também nesta localidade.

\section{DESCRIÇÃO DAS FORMAS}

\section{Estromatólitos colunares coniformes atribuídos a Conophyton}

A maior parte das formas observadas na região são de estromatólitos coniformes colunares não ramificados, com laminação parabólica a pontiaguda e zona axial evidentes em perfil longitudinal. A zona axial compreende um feixe central estreito definido pela inflexão das ápices das sucessivas lâminas cuja presença é uma das características essenciais do grupo Conophyton (Figuras 7,8). Também pode se inferir a forma cônica da laminação em cortes transversais pela diminuição do diâmetro dos traços circulares a elípticos da laminação até o centro do estromatólito (Figuras 7D, 11). É a forma predominante nas pedreiras Lavrinhas e Indumine/ Chiquinho de Barros, tendo sido identificado também na Fazenda Santo Antônio por Fairchild \& Theodorovicz (1989).

Os Conophyton de Indumine e Chiquinho de Barros são diferentes daqueles de Lavrinha. Apresentam colunas agregadas formando estruturas compostas ou coalescidas de indivíduos de diversos tamanhos. Algumas colunas, em corte transversal, mostram desenvolvimento lateral assimétrico (Figuras 3A, 6A), exemplificado por uma espécie de capa contornando parcialmente uma ou mais colunas com a mesma laminação fina de dentro das colunas individuais. Isto foi observado principalmente em Lavrinhas, mas também foi constatado em Indumine (Figura 3B). As colunas são paralelas, não ramificadas, com atitude normal, e estão agrupadas de forma contígua a próxima, formando agrupamentos interligados (Figura 7A). Devido à deformação em Indumine e
Chiquinho de Barros, a orientação original não é mais observada, mas as colunas encontram-se paralelas, orientadas tectonicamente (Figura 7F). As colunas são cilíndricas, simples (Figura 7A), lisas (Figuras 7A, E) com contornos transversais geralmente elípticos a oblongos (Figuras 6B, C), existindo formas equidimensionais arredondadas/circulares (Figura 7D) a poligonais (Figura 6A). O espaço intercolunar é pequeno, variando de 0,5 a $2 \mathrm{~cm}$. Quando calculada a razão entre a separação intercolunar e o diâmetro das colunas, obteve-se um valor muito baixo (menor de 0,1). Em Lavrinhas as formas são grandes, comumente com $30 \mathrm{~cm}$ de eixo maior em planta, variando entre $10 \mathrm{e} 70 \mathrm{~cm}$ (Figuras 3B, 7F). Em Indumine e Chiquinho de Barros ocorrem formas entre $4 \mathrm{~cm}$ e, excepcionalmente, $60 \mathrm{~cm}$ (Figuras 3B, 7F).

A altura das colunas observadas chega a no mínimo $1 \mathrm{~m}$ (Figura 7A). O perfil laminar é de modo geral pontiagudo (Figuras 7A, B, E e F), mas em cortes axiais demonstra ser pontiagudo com zona axial (Figuras 7C, F; 8A, B). Em Lavrinhas, o ângulo apical é de $60^{\circ}$ em média ( 8 medidas), em cortes no eixo maior e de $40^{\circ} \mathrm{em}$ cortes no eixo menor (Figuras 7A, B). O ângulo apical em Indumine é entre $40^{\circ}$ no eixo maior e $20^{\circ}$ no eixo menor, em média ( 9 medidas) menor, devido ao achatamento tectônico (Figura 7F). Em uma amostra deformada de Chiquinho de Barros (GP/6T-15 a, b) (Figura $8 \mathrm{~A}$ ), este ângulo é pequeno, $15^{\circ}$ no eixo menor, com um ângulo calculado (por trigonometria) de apenas $25^{\circ}$ no eixo maior. O relevo sinótico é alto, de $20 \mathrm{~cm}$ em formas com cerca de $20 \mathrm{~cm}$ de eixo maior. Considerando um ângulo apical médio de $60^{\circ}$ no eixo maior em Lavrinhas, e o tamanho do eixo maior, pode-se calcular o relevo sinótico. Assim uma forma de $10 \mathrm{~cm}$ de eixo maior teria cerca de $9 \mathrm{~cm}$ de relevo sinótico. Já formas maiores com $70 \mathrm{~cm}$ de eixo maior, poderiam alcançar até $60 \mathrm{~cm}$ de relevo. Em Indumine, foi observada uma forma com pelo menos $60 \mathrm{~cm}$ de eixo maior com um relevo sinótico de $60 \mathrm{~cm}$. O relevo sinótico pode ter sido maior até que o próprio diâmetro da coluna. A zona axial é muito estreita, geralmente de 3 a $4 \mathrm{~mm}$ de largura (Figuras 7C, 8B), com até $1 \mathrm{~cm}$ (eixo maior), excepcionalmente, ou, em amostras muito deformadas, apenas $2 \mathrm{~mm}$ (eixo menor) (Figura 8A). A partir dos traços axiais, ou seja, as linhas unindo os pontos de maior espessura em lâminas sucessivas da zona axial, pode-se deduzir o grau de herança laminar e distinguir algumas formas de Conophyton. Em amostras de Lavrinhas e Chiquinho de Barros, a zona axial e seus respectivos traços indicam grau de herança laminar da zona axial alto a médio (Figuras 8A, B), conforme designação de Walter (1972).

A laminação é fina em Lavrinhas, mas mal preservada, ressaltando um padrão de "manchas" claras e escuras, concordantes ou discordantes com a laminação (Figuras 7B, C, D), e nas porções mais escuras a laminação é melhor definida. Este padrão decorre das alterações na laminação original devido à dolomitização e/ou à deformação. Em Indumine e Chiquinho de Barros as lâminas também são finas, porém mais nítidas. Quanto à laminação em si, tanto em Lavrinhas como em Indumine e Chiquinho de Barros observa-se um 
padrão de alternância sub-milimétrica a milimétrica de lâminas claras e escuras (Figura 8A, B). Não apresenta ondulação, ou seja, seu grau de curvatura é simples.

Apesar da dificuldade de visualizar a laminação em amostras de mão e no campo em Lavrinhas, observou-se boa preservação em lâminas petrográficas (Figura 8A, B), alcançando até classe 1, nas melhores amostras (classificação de Walter, 1972). Foram tomadas 106 medidas de lâminas escuras (L2) e 107 de lâminas claras (L1) em duas lâminas petrográficas da amostra GP/3T-539-A (Figura 8C). Os valores obtidos estão entre 0,01 e $0,38 \mathrm{~mm}$, tanto para as lâminas escuras (L2) quanto para as claras (L1), com maior freqüência de valores para L2 entre 0,04 e 0,18 mm e para L1 entre 0,04 a 0,26 (Figura 8E). As lâminas escuras e claras têm picos principais menores que $0,1 \mathrm{~mm}$, sendo que as claras alcançam maiores espessuras. Nota-se, por este gráfico (Figura 8E), que as lâminas escuras e claras tem pico principal menor que $0,1 \mathrm{~mm}$, sendo que as claras alcançam maiores espessuras.

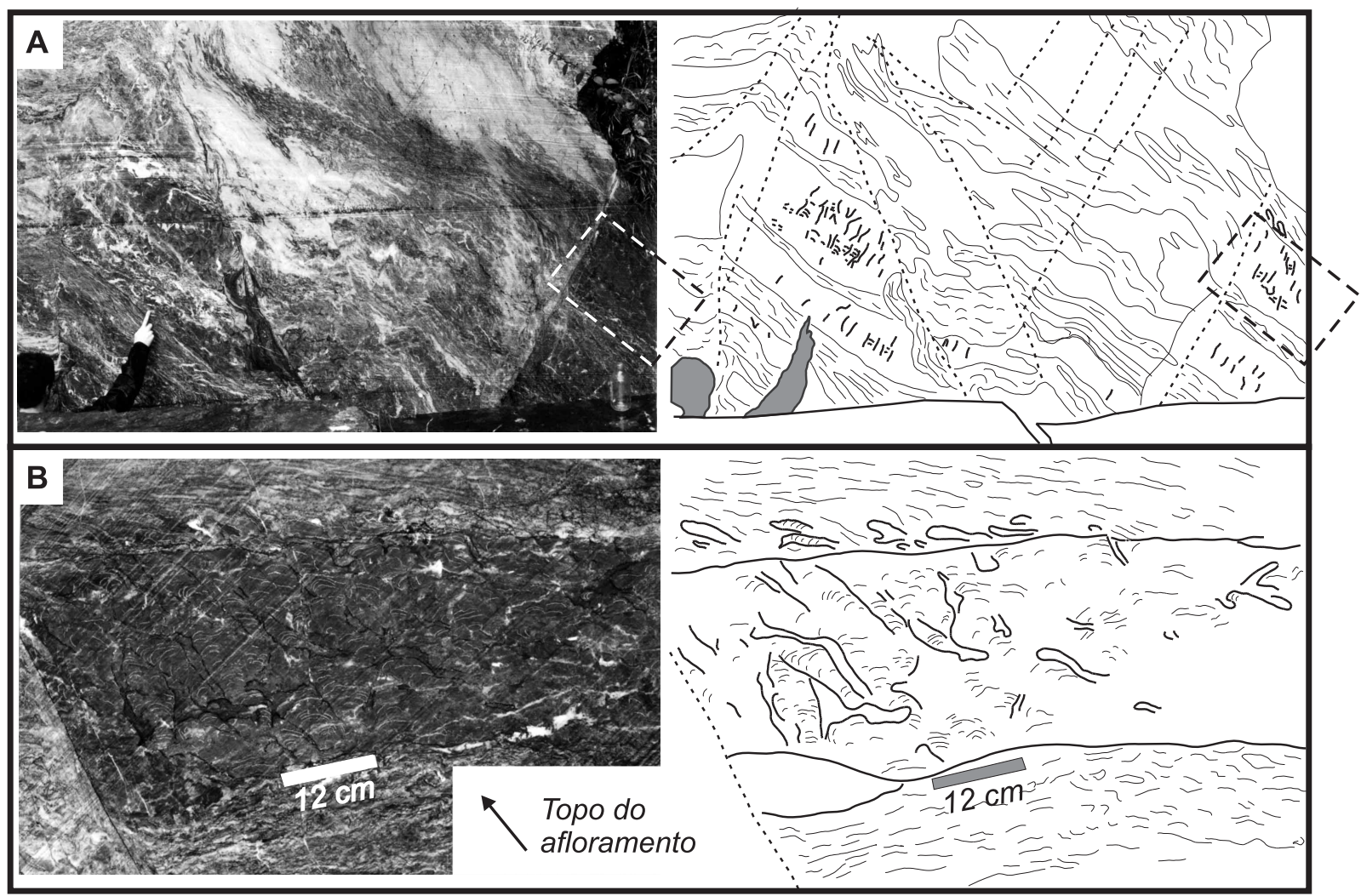

Figura 5. Fazenda Santo Antônio: A, frente abandonada (linhas pontilhadas = fraturas e falhas; linhas sólidas curtas = estromatólitos; $\mathbf{B}$, maior detalhe do retângulo em $\mathbf{A}$ (camada boudin) com desenho interpretativo (linhas sólidas = margens de estromatólitos).

Figure 5. Fazenda Santo Antônio: A, abandoned quarry (dotted lines = fractures and faults; short solid lines = stromatolites); $\mathbf{B}$, rectangle in $\mathbf{A}$ (boudin bed) (solid lines = margins of stromatolites).

Fairchild (1977) também apresenta valores de espessuras de laminação para as mesmas lâminas analisadas, obtidos a partir de 170 medidas de L2 e 165 de L1.Os valores variam de L2 entre 0,01 e 0,2 e de L1 entre 0,01 e 0,46, com uma maior concentração para L2 entre 0,01 e $0,1 \mathrm{~mm}$ e para L1 entre 0,01 a 0,26. Já em lâminas petrográficas de Indumine, existem casos de preservação relativamente boa (classe 2 de Walter, 1972), com a laminação clara e escura bem definida (Figura 8D). Em algumas amostras muito deformadas, a laminação é mal preservada, com lâminas claras e escuras apagadas, restando apenas uma laminação vestigial de coloração clara e homogênea. Ainda em lâmina petrográfica, verificou-se que as margens das colunas são bastante irregulares e tectonizadas (cisalhadas), com sedimento intercolunarfoliado. Não foram tomadas medidas de espessura de laminação para as lâminas de Indumine, devido à recristalização, com cristais de calcita fortemente orientados. Desenhos da laminação elaborados a partir de fotografias de lâminas mostram bem o aspecto da laminação fina e a distribuição das lâminas claras e escuras (Figura 8C), e uma maior densidade de lâminas claras do que de escuras. Esta forma está classificada (Fairchild, 1977) como Conophyton garganicum.

\section{Estromatólitos colunares ramificados}

São formas colunares ramificadas, com laminação convexa e contornos transversais alongados. Exemplos semelhantes ocorrem em Lavrinhas, Nova Campina e Brancal-Indumine I, e em outras localidades menores. Não foram detectadas em Indumine - Chiquinho de Barros, nem na Fazenda Santo Antônio. Estas formas foram observadas apenas nos metacalcários dolomíticos e em Brancal-Indumine I, apresentando silicificação parcial, com lâminas finas de sílica, con- 


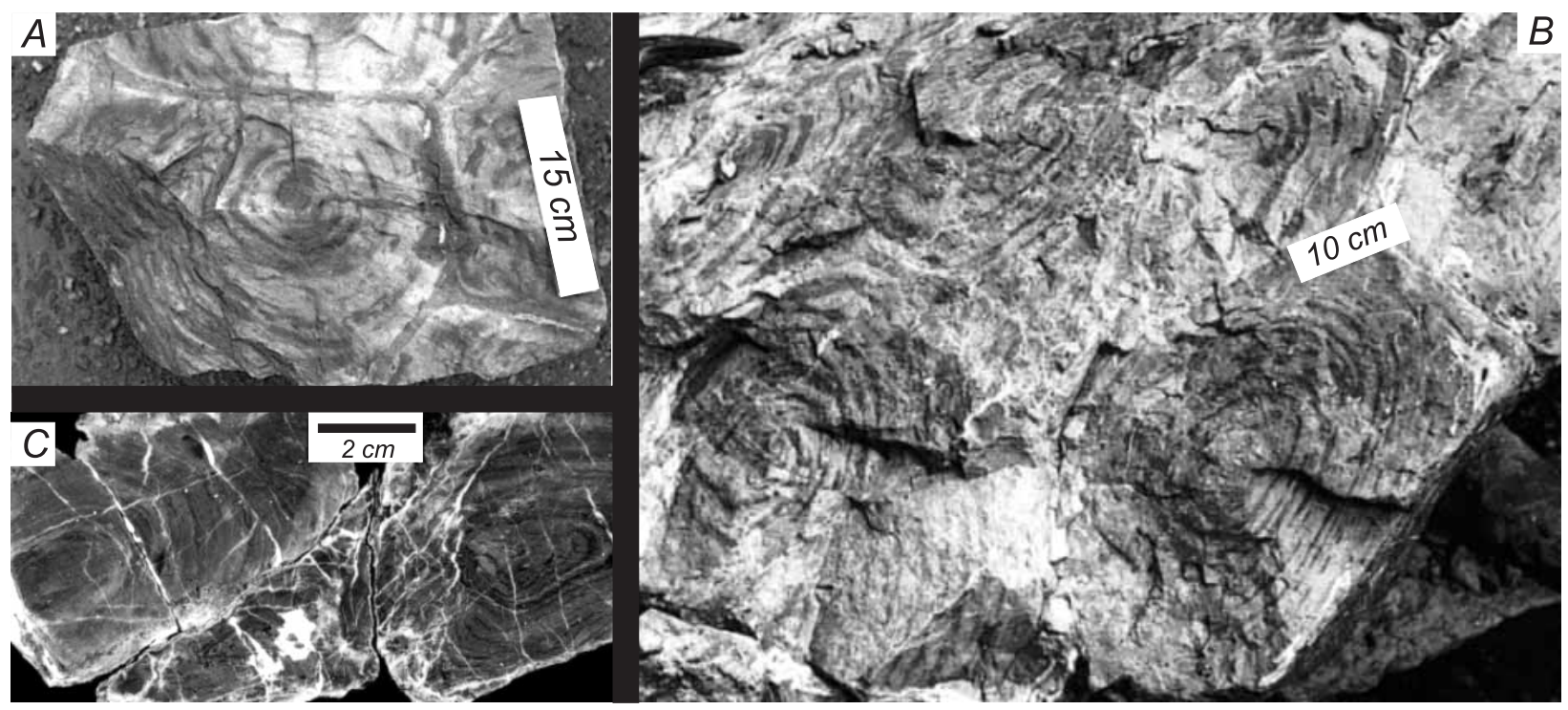

Figura 6. Vistas em planta de estromatólitos colunares coniformes muito próximos entre si: A, colunas assimétricas, com contornos poligonais, Lavrinhas; B, colunas com contornos elípticos, Lavrinhas; C, colunas com contornos elípticos, Fazenda Santo Antônio. Figure 6. Plan views of closely spaced coniform columnar stromatolites: A, asymmetric columns with polygonal outlines, Lavrinhas; B, columns with elliptical outlines, Lavrinhas; C, columns with elliptical outlines, Fazenda Santo Antônio.

cordantes com a laminação carbonática, sílica dispersa em meio ao carbonato, bem como sílica posterior em fraturas ou preenchendo vazios entre a laminação estromatolítica. Em Lavrinhas a preservação é de classe 2 para as colunas e de 1 a 2 para a laminação. Quando silicificadas, a preservação é melhor chegando até a classe 1 , tanto para as colunas quanto para a laminação. As descrições de Collenia itapevensi feitas por Almeida (1944: 96-100) se assemelham, na maior parte, a estromatólitos deste tipo, pois em corte longitudinal aparecem como formas colunares paralelas a ligeiramente oblíquas, com laminação convexa e espaços intercolunares de 3 a $10 \mathrm{~mm}$ de largura e, em cortes transversais, contornos circulares, elípticos a poligonais, com laminação concêntrica, tangencial nas margens (Figura 9). As colunas são paralelas, com atitude normal, muito próximas, separadas por apenas 1 a 3 mm (Figuras 9A, E). A razão área total (AT)/área das

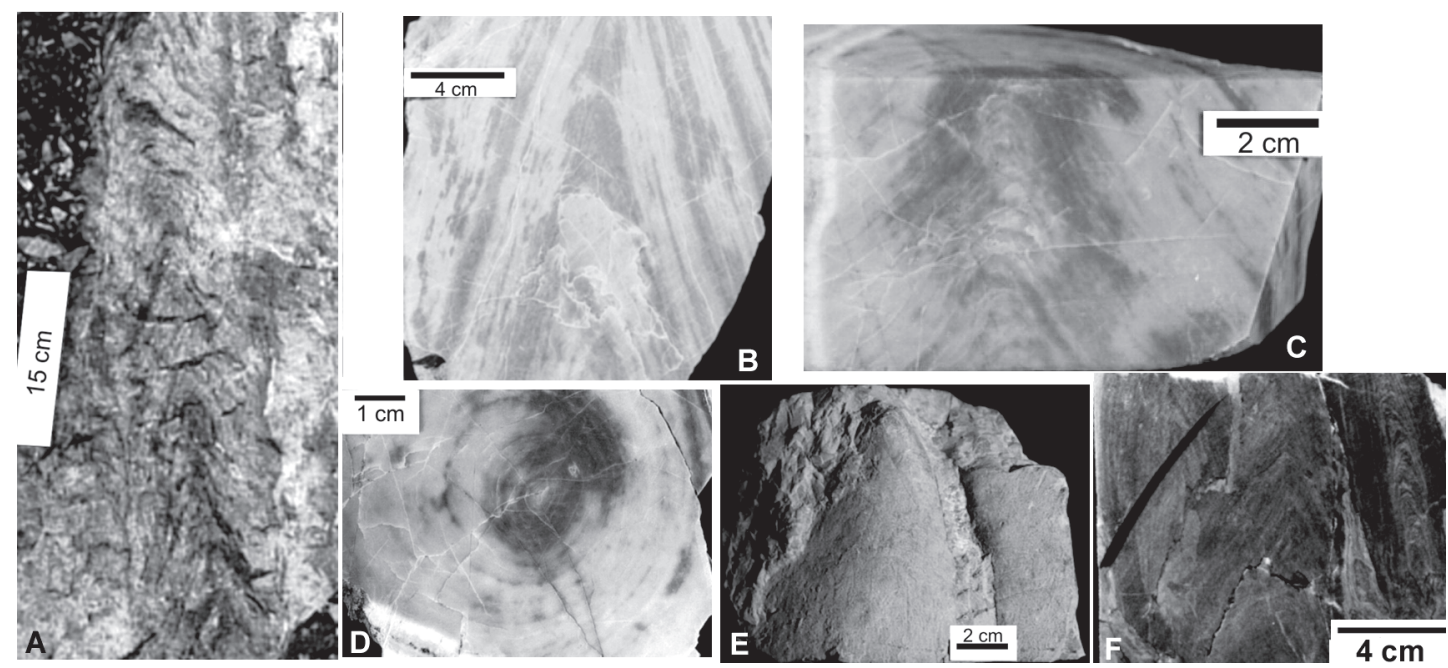

Figura 7. Estromatólitos colunares coniformes: A, coluna longa com laminação cônica, Lavrinhas; B, corte longitudinal de coluna com laminação cônica e preservação irregular da laminação original (manchas escuras), Lavrinhas (GP/6E-119); C, corte longitudinal de coluna mostrando laminação cônica e zona axial, Lavrinhas (GP/6E-125); D, coluna com contorno transversal circular (GP/6E-125); E, preservação tridimensional do ápice cônico de uma coluna, Lavrinhas (GP/6E-126); F,corte longitudinal mostrando três colunas deformadas, próximas entre si, com laminação cônica e zona axial evidente na coluna à direita, Indumine (GP/6E-114).

Figure 7. Coniform columnar stromatolites: A, long column with conical lamination, Lavrinhas; B, longitudinal cross-section of column with irregularly preserved lamination (best in darker patches), Lavrinhas (GP/6E-119); C, longitudinal cross-section of column showing conical lamination and axial zone, Lavrinhas (GP/6E-125); D, column with circular transverse outline (GP/6E-125); E, three-dimensionally preserved conical apex of column, Lavrinhas (GP/6E-126); F, longitudianal cross-section through three closely spaced deformed columns, with conical lamination and axial zone evident in the column on the right, Indumine (GP/6E-114). 
colunas (AC), medida em corte transversal em 4 amostras (Figuras 9F, G, H) é cerca de 0,9, indicando uma alta densidade de colunas. As colunas apresentam forma cilíndrica simples (Figuras 9B, C, E) a cilíndrica ramificada em corte longitudinal (Figura 9A), e margens lisas (Figuras 9B, C, E), com até $35 \mathrm{~cm}$ de altura (parcial). A freqüência de ramificação é de 0,2 em média, ou seja, pouco freqüentes; são paralelas do tipo a (Walter , 1972) mas também ocorrem projeções em nicho (Figura 9A). Em planta são geralmente elípticas, oblongas (Figura 9H) a equidimensionais poligonais (Figura 9G). As formas elípticas possuem de 5 a $14 \mathrm{~cm}$ (parcial) no eixo maior e de 2 a $12 \mathrm{~cm}$ (parcial) no eixo menor em Lavrinhas, e de 5 a 8 $\mathrm{cm}$ (parcial) no eixo maior e de 2 a $6 \mathrm{~cm}$ (parcial) no eixo menor em Nova Campina. Os contornos alongados são, grosso modo, paralelos entre si. As colunas são por vezes coalescidas. Constituem formas relativamente altas, compridas e estreitas, muito próximas umas das outras. O perfil laminar varia de pouco (Figura 9A) a muito convexo (Figura 9E), até parabólico (Figura 9B), principalmente em função da orientação do corte longitudinal analisado. Paralelo ao eixo transversal maior, o perfil laminar apresenta-se planar a moderadamente convexo, enquanto no sentido perpendicular, o perfil é mais convexo a parabólico. O relevo sinótico é relativamente alto, variando de 1 a $6 \mathrm{~cm}$. Possui grau de herança laminar alto, variando de simétrico (Figuras 9B, E) a assimétrico (Figura 9C), com perfil laminar muito convexo a parabólico. A estrutura laminar marginal é infletida, geralmente com superposição extensa de lâminas anteriores (Figura 9B), mas ocorrendo também formas sem superposição e com superposição parcial. Apesar do pouco espaço entre as colunas, não apresentam conexões entre colunas (pontes). Observa-se uma laminação fina, que possui alternância de camadas cinza médias e cinza claras (Figura 9B), sem ritmicidade evidente. Ocasionalmente, ao atingir as margens, a laminação torna-se mais escura, tal como o sedimento entre as colunas (Figura 9). Apresenta, como as formas cônicas, porções mais escuras onde a laminação está melhor preservada entre as mais claras. A espessura da laminação, medida em uma lâmina petrográfica da amostra GP/6E - 132, revelou lâminas escuras entre 0,05 e 0,25 mm de espessura e lâminas claras entre 0,1 e $0,55 \mathrm{~mm}$.

\section{Estromatólitos colunares não ramificados}

São formas colunares não ramificadas com laminação parabólica e contornos transversais elípticos. Foram observadas, principalmente, em Brancal-Indumine I, ocorrendo também nas localidades de Lavrinhas e Indumine. Em Nova Campina e Taquari-Guaçu, há exemplares que podem ser atribuí-

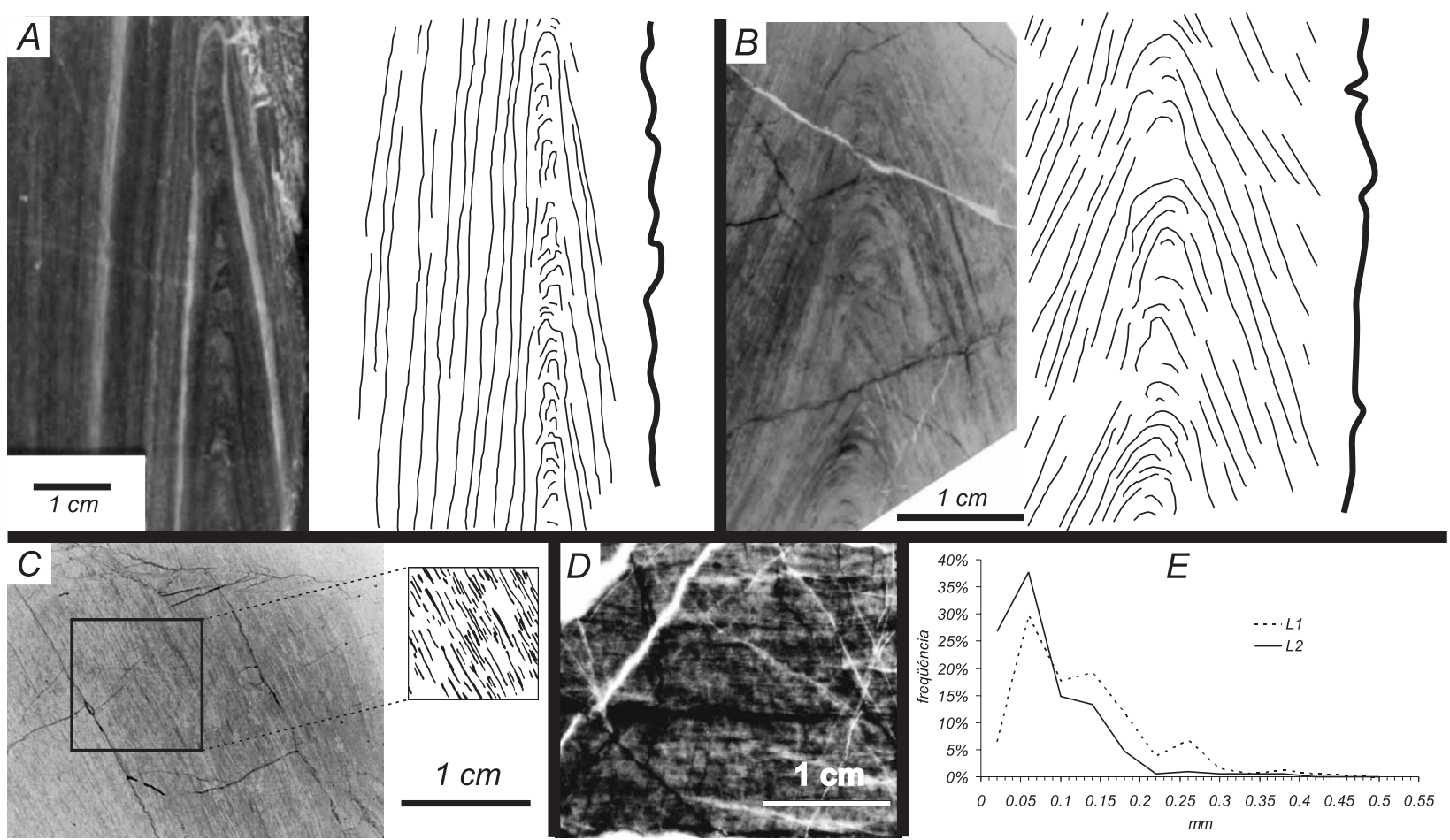

Figura 8. Zona axial e laminação de estromatólitos coniformes: A, coluna lateralmente comprimida com zona axial evidente; à direita, o traço axial, Chiquinho de Barros (GP/6T-15 a, b); B, coluna com zona axial e traço axial, Lavrinhas (GP/3T-539 a); C, detalhe da laminação de estromatólito coniforme, Lavrinhas (GP/3T-539 a); D, detalhe da laminação de estromatólito coniforme, Indumine; E, gráfico da freqüência relativa da espessura das lâminas escuras $(L 2, n=276)$ e claras $(L 1, n=272)$ do estromatólito ilustrado em $\mathbf{B}$ e $\mathbf{C}(\mathrm{GP} / 3 \mathrm{~T}-539$ a; dados de Fairchild, 1977 e Sallun Filho, 1999).

Figure 8. Axial zone and lamination in coniform stromatolites: A, laterally compressed column with distinct axial zone and axial trace, Chiquinho de Barros quarry (GP/6T-15 a, b); B, column with axial zone and axial trace, Lavrinhas (GP/3T539 a); C, detail of lamination in coniform stromatolite, Lavrinhas (GP/3T-539 a); $\mathbf{D}$, detail of lamination in coniform stromatolite, Indumine; $\mathbf{E}$, graph of relative frequency of thickness of dark laminae $(L 2, n=276)$ and light laminae $(L 1, n=272)$ in the coniform stromatolite shown in $B$ and $C(G P / 3 T-539$ a, data from Fairchild, 1977 and Sallun Filho, 1999). 
dos a esta forma, porém a má preservação impede uma caracterização definitiva. Difere da forma colunar ramificada, pela ausência de ramificação, laminação mais convexa, contorno em planta elíptico, não alongado, e tamanho maior. Apesar da laminação convexa, não são formas cônicas, estando orientadas paralelamente, com atitude normal, próximas, com espaço entre colunas de 1 a 3 cm (Figuras 10A,B,D). São colunas cilíndricas retas, não ramificadas, com margens lisas (Figura 10) e até $1 \mathrm{~m}$ metro de altura. Os contornos, em planta, são arredondados a elípticos (Figura 10G), de 10 a $20 \mathrm{~cm}$ no eixo maior e de 5 a 15 cm no eixo menor. Comumente, as lâminas são parabólicas ou moderadamente a muito convexas (Figura 10A,B,C,D,F). Em cortes tangenciais a laminação é pouco convexa (Figura $10 \mathrm{E}$ ), formando um ângulo de aproximadamente $100-110^{\circ} \mathrm{em}$ Brancal-Indumine I. Em Indumine, este ângulo é menor, cerca de $85^{\circ}$, o que pode refletir a forte deformação neste local. $\mathrm{O}$ grau de herança laminar é alto e simétrico a assimétrico e estrutura laminar marginal infletida, sem superposição (Figura 10C). O relevo sinótico varia entre 2 e $10 \mathrm{~cm}$.

Em Brancal-Indumine I, os estromatólitos apresentam silicificação parcial, da mesma forma que na forma colunar ramificada. Esta silificação preenche algumas fraturas e espaços entre as lâminas, especialmente, no vértice da laminação convexa, no espaço gerado pela deformação, sugerindo a existência de uma fase de silificação anterior e outra posterior ou concomitante com a deformação.

\section{INTERPRETAÇÕES PALEOAMBIENTAIS}

Em Indumine, os estromatólitos são compostos de metacalcário calcítico impuro, enquanto em Lavrinhas, de metacalcário dolomítico mais puro. O Conophyton de

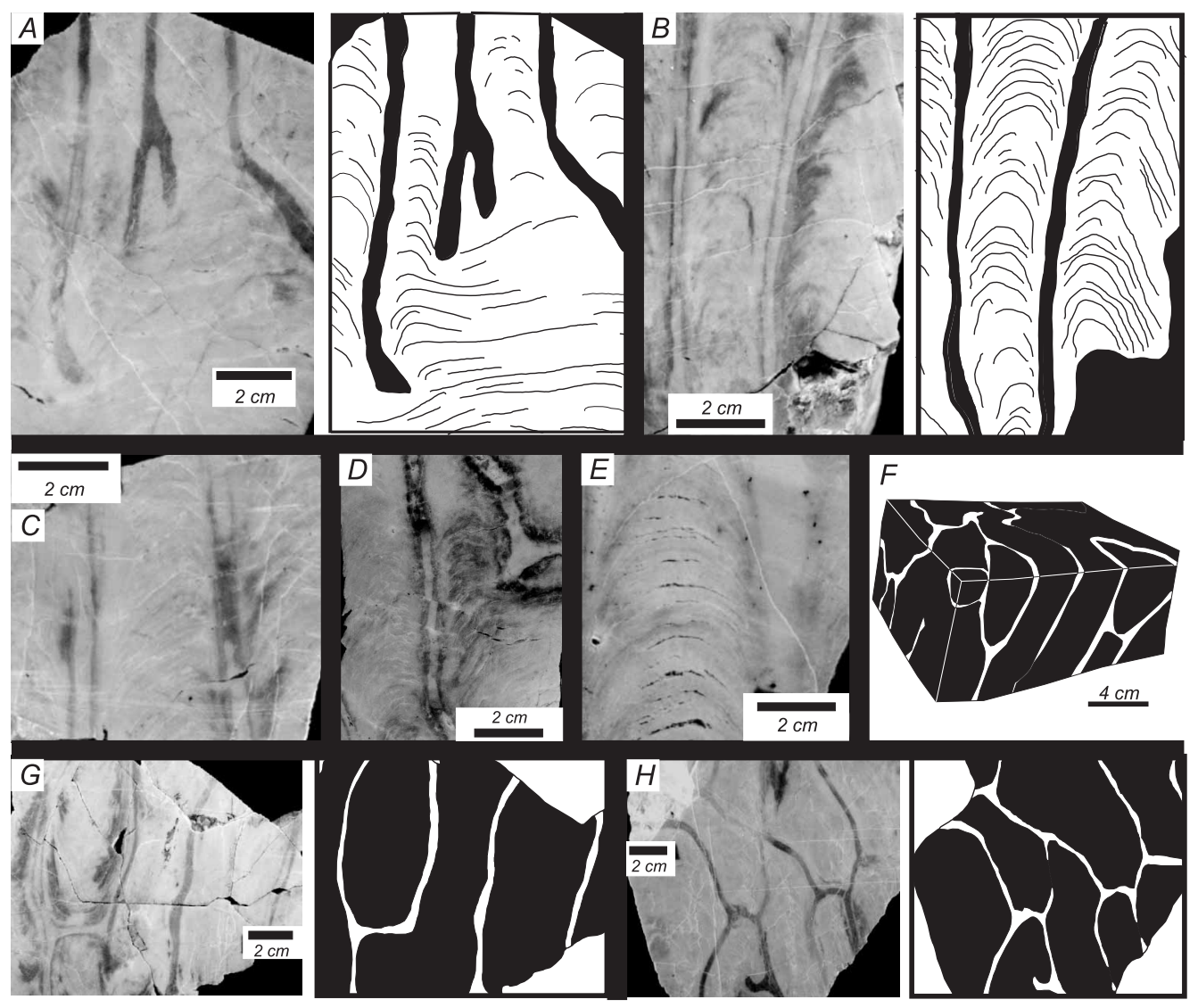

Figura 9. Estromatólitos colunares ramificados em cortes longitudinais $(\mathbf{A}-\mathbf{E})$ e transversais $(\mathbf{G}-\mathbf{H})$ e obliquo $(\mathbf{F})$ : $\mathbf{A}$, colunas com laminação fina, convexa a parabólica, , Lavrinhas (GP/6E-133); B, colunas paralelas com laminação muito convexa a parabólica, alternância de camadas claras e escuras, e margens nítidas, Lavrinhas (GP/6E-132); C, colunas paralelas com laminação convexa a parabólica, assimétrica, alternância de camadas claras e escuras, Nova Campina (GP/6E-139); D, parátipo de Collenia itapevensis, mostrando pequena projeção (GP/3T-80); E, colunas com laminação convexa, simétrica, parcialmente silicificadas, e lâminas escuras de sílica, Brancal-Indumine I (GP/6E140); F, bloco esquemático de uma amostra (GP/6E-134), Lavrinhas; G, colunas com contornos transversais elípticos a poligonais alongados e paralelos, Lavrinhas (GP/6E-132); H, colunas com contornos elípticos a poligonais, Lavrinhas (GP/6E-133).

Figura 9. Branched columnar stromatolites in longitudinal $(\mathbf{A}-\mathbf{E})$ and transverse $(\mathbf{G}-\mathbf{H})$ and oblique views $(\mathbf{F})$ : A, columns with fine, convex to parabolic lamination, Lavrinhas (GP/6E-133); B, parallel columns with convex to parabolic lamination, alternation of light and dark laminae, and distinct margins, Lavrinhas (GP/6E-132); C, parallel columns with asymmetrical convex to parabolic lamination and alternation of light and dark laminae, Nova Campina (GP/6E-139); D, paratype of Collenia itapevensis, showing a small projection (GP/3T-80); E, columns with convex symmetrical lamination, partially silicified, light and dark laminae, Brancal-Indumine I (GP/6E-140); F, schematic block of a sample (GP/6E-134), Lavrinhas; G, columns with parallel, elongate, elliptical to polygonal transverse contours, Lavrinhas (GP/6E-132); H, columns with elliptical to polygonal transverse cross-sections, Lavrinhas (GP/6E-133). 
Lavrinhas possui $2 \%$ de impurezas nas colunas e $5 \%$ no material intercolunar; o Conophyton de Indumine possui $10 \%$ de impurezas nas colunas e de 13 a $54 \%$ no material intercolunar. Estas impurezas são material não carbonático, como quartzo e argila. Apenas em Indumine e Chiquinho de Barros ocorrem metacalcários calcíticos impuros, pois predominam regionalmente os metacalcários dolomíticos mais puros, como os de Lavrinhas. Compõe dois tipos principais de bioermas: um tabular mais extenso e mais comum, desenvolvido em metacalcários dolomíticos, e outro dômico/lenticular raro e isolado, constituído de metacalcários calcíticos mais impuros. As colunas que ocorrem em Indumine, apesar de próximas, em geral são estreitas $(6$ a $10 \mathrm{~cm})$ e isoladas, diferentes das de Lavrinhas onde as colunas são maiores (10 a $30 \mathrm{~cm}$ ) e ocorrem agregadas, formando conjuntos maiores, com uma capa laminada envolvendo parte do conjunto. Em Lavrinhas ocorrem outras formas não cônicas e ramificadas associadas a Conophyton, que não estão presentes em Indumine. Considera-se que o grupo Conophyton ocorre em águas relativamente profundas, baseados na ausência de estruturas sedimentares de águas rasas associadas (Donaldson $\&$ Taylor, 1972). Hoffman (1976) estimou a profundidade de ocorrência de Conophyton, para a Formação Taltheilei (Paleoproterozóico do Canadá), entre 10 e 100 m, ou mais. Em águas com menos de $10 \mathrm{~m}$ de profundidade, Conophyton passaria para Jacutophyton, um estromatólito coniforme marcado pela abundância de pequenos ramos divergentes que saem da sua margem, e com menos de $1 \mathrm{~m}$ ocorreriam outras formas colunares não coniformes (Hoffman, 1976). A presença mais comum de formas maiores compostas, associadas a formas não cônicas em Lavrinhas, parece indicar menor profundidade da água e, consequientemente, uma luminosidade alta. Especula-se que a origem das estruturas compostas por estromatólitos individuais seja reflexo desta alta luminosidade, onde um crescimento lateral seria favorecido, como visto na Figura 11. Já em Indumine, as colunas mais estreitas e espaçadas bem como a presença de argila na rocha, permitem inferir que as condições eram de baixa luminosidade, favorecendo um maior crescimento vertical (Figura 11). A presença de até 50\% de impurezas (principalmente argila) no material intercolunar de Indumine é um valor incomum pois, provavelmente, esta quantidade de impurezas tornava a água turva, o que não é muito comum em um ambiente de formação de estromatólitos. As formas de Conophyton estudadas também foram atribuídas a um ambiente deposicional em águas relativamente profundas, abaixo da ação das ondas, com até algumas dezenas de metros, devido à abundância das formas cônicas e a ausência de evidências de retrabalhamento. Ambientes um pouco mais rasos estão evidenciados pelas formas estromatolíticas não cônicas, porém não são observados ambientes notadamente rasos na área. Os estromatólitos estariam distribuídos em ambiente de rampa, onde tanto as formas de Conophyton de

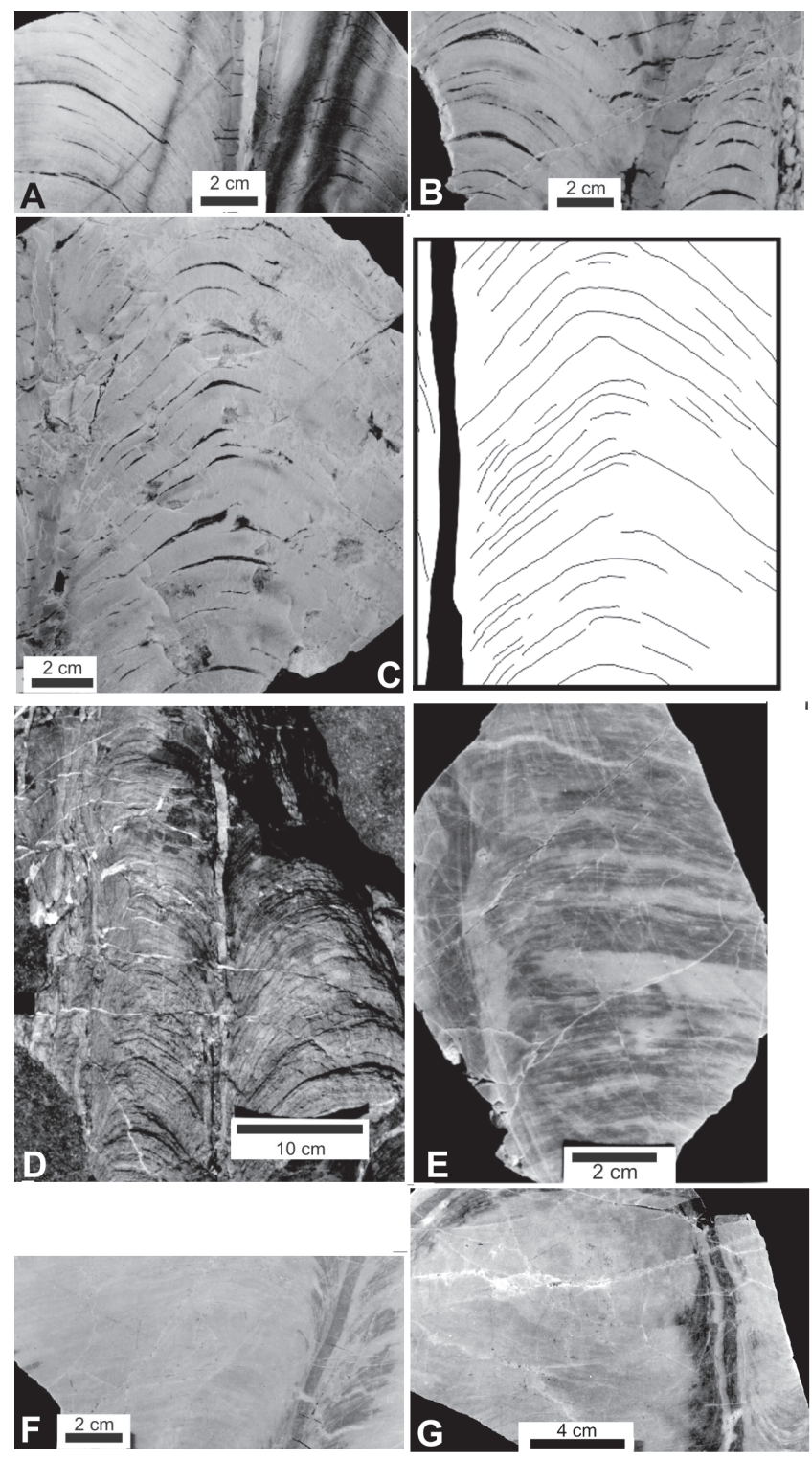

Figura 10. Modelo de desenvolvimento de Conophyton em águas bem iluminadas (Lavrinhas) e mal iluminadas (Indumine) (adaptado de Donaldson, 1976).

Figure 10. Model for development of Conophyton in well-lit waters (Lavrinhas) and in poorly illuminated waters (Indumine) (adapted from Donaldson, 1976).

Indumine quanto as de Lavrinhas foram formadas. Os estromatólitos individuais estariam distribuídos sobre o assoalho marinho, exibindo individualmente relevos de até $70 \mathrm{~cm}$. Considerando-se que eles poderiam formar estruturas compostas maiores, este relevo pode ter sido muito maior.

\section{AGRADECIMENTOS}

Às companhias Cimento Portland Itaú, da Pedreira Lavrinhas, e Cimento Portland Maringá, atual Minas Oeste, da Pedreira Indumine, sempre bastante prestativos e atenciosos nas visitas às pedreiras. À FAPESP pelo financiamento das pesquisas e bolsa de mestrado (WSF). 

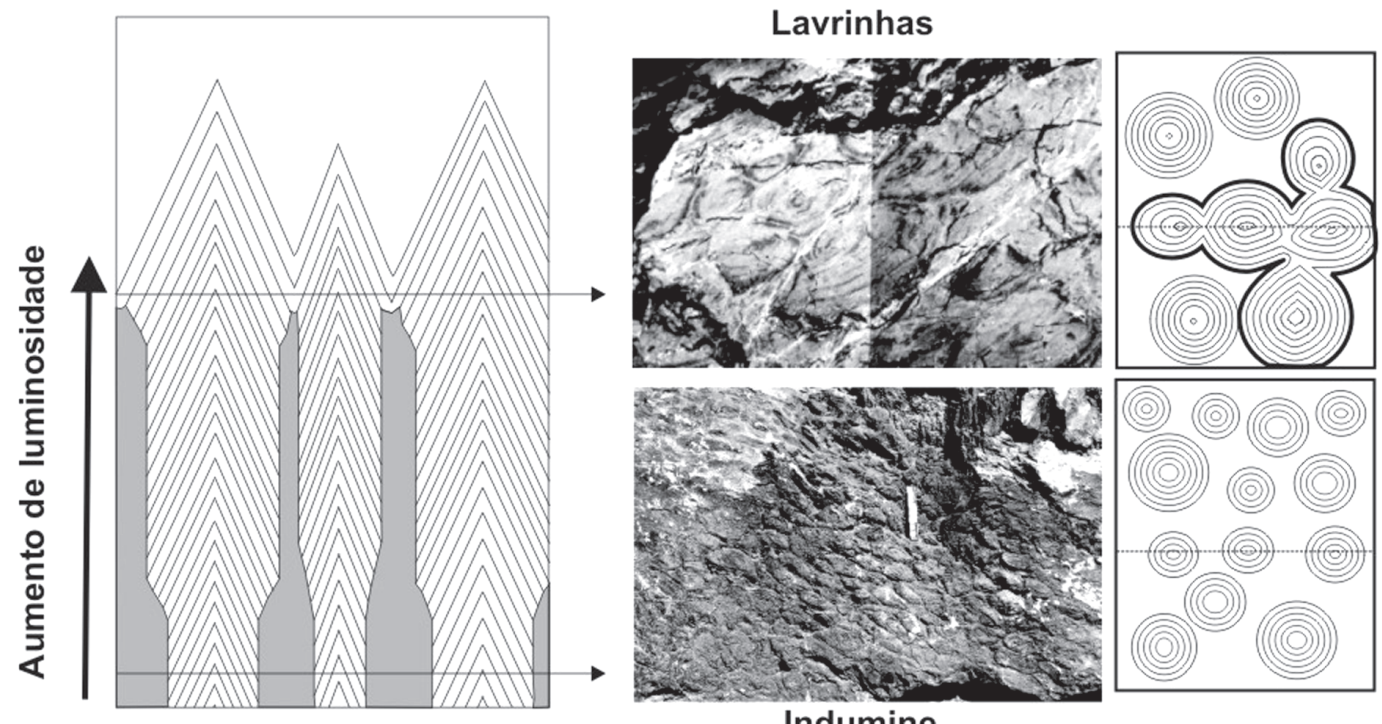

\section{Crescimento lateral e coalescência, colunas largas}

Figura 11. Modelo de desenvolvimento de Conophyton em águas bem iluminadas (Lavrinhas) e mal iluminadas (Indumine) (adaptado de Donaldson, 1976).

Figure 11. Model for development of Conophyton in well-lit waters (Lavrinhas) and in poorly illuminated waters (Indumine) (adapted from Donaldson, 1976).

\section{REFERÊNCIAS}

Almeida, F.F.M. de 1944. Collenia itapevensis sp. $n$. - um fóssil pré-cambriano do Estado de São Paulo. Boletim da Faculdade de Filosofia, Ciências e Letras da Universidade de São Paulo, Geologia, 45(1):89-106.

Almeida, F.F.M. de 1957. Novas ocorrências de fósseis no précambriano brasileiro. Anais da Academia Brasileira de Ciências, 29:63-72.

Bigarella, J.J. \& Salamuni, R. 1958. Estudos preliminares na série Açunguí VIII - A Formação Votuverava. Boletim do Instituto de História Natural, Geologia, 6 p. (Boletim 2).

Donaldson, J.A. 1976. Paleoecology of Conophyton and associated stromatolites in the Precambrian Dismal Lakes and Rae Groups, Canada. In: M.R. Walter (ed.) Stromatolites, Elsevier, p. 523534.

Donaldson, J.A. \& Taylor, A.H. 1972. Conical-columnar stromatolites and subtidal enviroment. American Association Petroleum Geologists Bulletin, 56:614.

Fairchild, T.R. 1977. Conophyton and other columnar stromatolites from the Upper Precambrian Açungui Group near Itapeva, SP, Brazil. In: SIMPÓSIO REGIONAL DE GEOLOGIA, 1, 1977. Atas, São Paulo, p. 179-198.

Fairchild, T.R. 1982. New stromatolites from the Upper Precambrian Açungui Group, eastern Paraná, Brazil, and their potential stratigraphic use. Boletim do Instituto de Geociências-USP, 13:43-50.

Fairchild, T.R. 1993. Um método prático de descrição de estromatólitos para o geólogo de campo. In: CONGRESSO BRASILEIRO DE PALEONTOLOGIA, 13, 1993. Resumos, São Leopoldo, p. 207.

Fairchild, T.R. \& Theodorovicz, A. 1989. Novas ocorrências de estromatólitos no Grupo Itaiacoca (Proterozóico médio a superior), sul do Estado de São Paulo. In: CONGRESSO BRASILEIRO DE PALEONTOLOGIA, 11, 1989. Resumos, Curitiba, p. 4.
Fairchild, T.R. \& Sallun Filho, W. (no prelo). Collenia itapevensis, o primeiro fóssil pré-cambriano brasileiro e sua importância no estudo de estromatólitos no Brasil. In: V. Mantesso Neto; A. Bartorelli; C.D.R.Carneiro; B.B. Brito Neves (eds.) Geologia do continente Sul-americano: evolução da obra de Fernando Flávio Marques de Almeida.

Hoffman, P. 1976. Environmental diversity of middle Precambrian stromatolites. In: M.R. Walter (ed.) Stromatolites, Elsevier, p. 599-611.

Hoffman, H.J. 1969. Atributes of stromatolites. Canadian Geological Survey, $58 \mathrm{p}$.

Marini, O.J. \& Bósio, N.J. 1971. Estromatólitos em dolomitos do Grupo Açungui. Anais da Academia Brasileira de Ciências, 43(1):161-175.

Marini, O.J.; Trein, E. \& Fuck, R. 1967. O Grupo Açungui no estado do Paraná. Boletim Paranaense de Geociências, 23/25:43104.

Prazeres Filho, H.J. dos; Guimarães, G.; Basei, M.; Siga Jr.; Reis Neto, J.M. dos; Campanha, G. \& Sallun Filho, W. 1998. Mapa geológico 1:50.000 da porção centro-sul da Faixa Itaiacoca PR. In: CONGRESSO BRASILEIRO DE GEOLOGIA, 40, 1998. Anais, Belo Horizonte, p. 36.

Reis Neto, J.M. dos 1994. Faixa Itaiacoca: registro de uma colisão entre dois blocos continentais no Neoproterozóico. Instituto de Geociências, Universidade de São Paulo, Tese de Doutoramento, $253 \mathrm{p}$.

Sallun Filho, W. 1999. Análise dos estromatólitos do Grupo Itaiacoca (Proterozóico), ao sul de Itapeva, SP. Instituto de Geociências, Universidade de São Paulo, Dissertação de Mestrado, $126 \mathrm{p}$.

Siga Jr., O.; Basei, M.A.S.; Sato, K.; Prazeres Filho, H.J. dos; Cury, L.F.; Weber, W.; Passarelli, C.R.; Harara, O.M. \& Reis Neto, J.M. dos 2003. U-Pb (Zircon) ages of metavolcanic rocks from the Itaiacoca Group: tectonic implications. Revista do Instituto de Geociências-USP, 3:39-49. 
Souza, A.P. 1990. Mapa geológico na escala 1:50.000 e esboço da evolução tectônica e sedimentar do Grupo Itaiacoca, nas folhas Barra do Chapéu e Ouro Verde - SP/PR. Instituto de Geociências, Universidade de São Paulo, Dissertação de Mestrado, $200 \mathrm{p}$.

Theodorovicz, A.; Câmara, M.M.; Morais, S.M.; Godoy, H.K. \& Takahashi, A.T. 1986. Projeto Engenheiro Maia-Ribeirão Branco. Relatório Final. CPRM/PROMINÉRIO. Relatório inédito.

Trein, E.; Reis Neto, J.M. dos; Biondi, J.C. \& Monastier, M.S.
1985. Revisão da Formação Itaiacoca: identificação de uma sequência metavulcano-sedimentar em Abapã (PR). In: SIMPÓSIO REGIONAL DE GEOLOGIA, 5, 1985. Atas, São Paulo, 1:169-185.

Walter, M.R. 1972. Stromatolites and the biostratigraphy of the Australian Precambrian and Cambrian. Palaeontological Association of London, Special Papers in Palaeontology, 190 p. (n. 11).

Received May, 2004; accepted October, 2004. 